\title{
Higher Hemoglobin Levels Are Associated With Better Physical Performance Among Older Adults Without Anemia: A Longitudinal Analysis
}

Ligiana Pires Corona ( $\square$ ligiana.corona@fca.unicamp.br)

University of Campinas (UNICAMP)

Flavia Cristina Drummond Andrade

University of Illinois Urbana-Champaign

Tiago Silva Alexandre

Federal University of Sao Carlos

Tábatta Renata Pereira Brito

Federal University of Alfenas, Rua Gabriel Monteiro da Silva

Daniella Pires Nunes

University of Campinas (UNICAMP)

Yeda Aparecida Oliveira Duarte

University of São Paulo

\section{Research Article}

Keywords: hemoglobin, physical performance, older adults, SABE study, Brazil.

Posted Date: August 17th, 2021

DOI: https://doi.org/10.21203/rs.3.rs-736515/v1

License: (1) This work is licensed under a Creative Commons Attribution 4.0 International License.

Read Full License 


\section{Abstract \\ Background}

Anemia is the most common hematological abnormality among older adults, and it is associated with decreased physical performance. But the role of hemoglobin in the absence of anemia remains unclear. Thus, this study aimed to assess the impact of hemoglobin levels on physical performance in Brazilian older adults without anemia.

\section{Methods}

The study is longitudinal in that it relies on two waves of the Saúde, Bem-Estar e Envelhecimento (SABE; Health, Well-being, and Aging) study: 2010 and 2015-2016. Mixed-effects linear regression was used to determine the effects of the hemoglobin concentrations on the Short Physical Performance Battery-SPPB over time among the 1,020 who had complete data and did not have anemia in 2010. In the follow-up, there were 562 without anemia. Analyses were stratified by sex.

\section{Results}

In analyses adjusted for age, education, grip strength, comorbidities, and body mass index, hemoglobin levels were positively associated with physical performance scores among older women $(\beta=0.15, p<$ $0.05)$ and men $(\beta=0.18, p<0.05)$ without anemia.

\section{Conclusion}

Our study demonstrates that higher hemoglobin levels were associated with better physical performance among older men and women without anemia. This finding is important because, in clinical practice, most health professionals focus on the World Health Organization definition of anemia. Our study suggests the importance of hemoglobin levels among older adults, even those without anemia.

\section{Background}

It is well-known that anemia, the most common hematological abnormality among older adults, is a major health problem associated with decreased physical performance, reduced mobility, increased functional dependence, and higher mortality (1-6). However, there is some debate whether the criteria adopted by the World Health Organization (WHO) to define anemia are adequate for older adults. Previous studies found disability and mortality risk gradients even within the WHO normal hemoglobin $(\mathrm{Hb})$ range. These studies suggest that $\mathrm{Hb}$ levels higher than current cutoffs for anemia treatment might offer a clinical advantage $(4,7,8)$. Therefore, it is important to explore more broadly the impact of hemoglobin levels, rather than anemia thresholds, on physical performance. 
A limitation in the past studies is that most that analyzed the association between $\mathrm{Hb}$ levels on physical function are cross-sectional, and those that have used longitudinal data have focused on the effect of baseline $\mathrm{Hb}$ levels on physical function (9-11). Chaves et al. (1) conducted a cross-sectional study with older women from the Women's Health and Aging Studies I and II, which found that mobility difficulty was greater among those participants with lower $\mathrm{Hb}$ levels. A study conducted in Australian men described that each $1 \mathrm{~g} / \mathrm{dL}$ increase in $\mathrm{Hb}$ was strongly associated with a reduced risk of slow walking speed, poor grip strength, inability to perform chair stands, ADL, and IADL disabilities (12). Tseng et al. (2021) found that slower gait speed was significantly associated with $\mathrm{Hb}$ levels, but the associations disappeared when $\mathrm{Hb}$ values were dichotomized according to the WHO anemia criteria in Taiwanese older adults (11). Marzban et al. (2021) also showed a short review in their paper with several other studies (10), but none discussed this effect in individuals without anemia.

The few studies that have considered $\mathrm{Hb}$ changes have produced conflicting results, and some have analyzed narrow populations. For example, Zakai and colleagues (2005) reported that lower baseline $\mathrm{Hb}$ levels and incident anemia were associated with lower gait speeds among women at follow-up even though the change in $\mathrm{Hb}$ levels over time was not statistically significant (4). Hirani et al. (2016), in a sample of Australian men, showed that for every $1 \mathrm{~g} / \mathrm{dL}$ increase in $\mathrm{Hb}$, there was a significant reduction in risk of sarcopenia, slow walking speed, poor grip strength, inability to perform chair stands, and problems with activities of daily living (ADLs) and instrumental activities of daily living (IADLs) (12). Yoshimura et al. (2021) showed that the change in $\mathrm{Hb}$ levels was positively associated with the Functional Independence Measure - motor efficacy, but the sample was restricted to stroke patients with anemia who had been hospitalized (13).

Cross-sectional studies in low and middle-income countries (LMIC) have explored the associations between hemoglobin or anemia and several outcomes, such as higher health services utilization, disability, frailty, and mortality $(6,8,14-16)$. Still, no longitudinal studies have examined the role of $\mathrm{Hb}$ on physical performance. Payne et al. (2018) analyzed cross-sectional data from a population-based study of rural South African men and women aged 40 and over and found that $\mathrm{Hb}$ concentration was independently associated with grip strength in women, but not in men, and did not observe associations between $\mathrm{Hb}$ and walking speed (9). On the other hand, a study conducted with Iranian older adults found an association between anemia and walking speed only among men in sex-stratified analyses, but they did not analyze continuous $\mathrm{Hb}$ levels (10).

There is some evidence that the association between $\mathrm{Hb}$ and functionality may be different in men and women. However, the differences according to sex are not adequately explored. For instance, in a study based in Japan, Sawada et al. (2021) showed low Hb was associated with worse scores in IADLs and cognition in women but not in men (17). A study based in China, Li, Chen, and Han (2021) showed that $\mathrm{Hb}$ levels predict frailty in women over 60 but not their male peers (18).

Thus, this study aimed to address some of the limitations of past studies. To do so, we assess the impact of hemoglobin levels on physical performance in Brazilian older adults without anemia stratified by sex 


\section{Methods}

\section{Design and Participants}

Data from the Saúde, Bem-Estar e Envelhecimento (SABE; Health, Well-being, and Aging), a multiplecohort study of Brazilian older adults that began in 2000 , are used in this study. SABE is based on a probabilistic sample of adults aged $\geq 60$ years residing in the city of São Paulo $(n=2,143)$. Follow-ups were conducted in 2006, 2010, and 2015-2016. A representative sample of older adults aged 60 to 64 years was added to the study in each new wave. Details on the methodology of the study have been published previously $(6,8)$. The Research Ethics Committee at the University of São Paulo approved all waves of the SABE Study. Participation was voluntary, and a signed informed consent form was obtained from all participants in each wave. All of the procedures followed the ethical standards of the institutional and national research committee and the 1964 Helsinki declaration.

For this study, we focus on the last two waves as blood samples were first collected in 2010. In 2010, there were 1,344 participants aged 60 and older, but 89 had incomplete data on blood parameters and 133 on selected variables. Another 102 were anemic. Therefore, the 2010 sample is restricted to 1,020 individuals. In 2015, 634 individuals who were reinterviewed had complete data on covariates. Among these, 72 developed anemia, leaving a total of 562 to be included in the follow-up.

\section{Measures and procedures}

Data collection included face-to-face interviews using a standardized questionnaire, measurement of anthropometric data and physical performance, and collection of physiological specimens of blood and urine.

The outcome measure, physical performance, was assessed in both waves using the Short Physical Performance Battery - SPPB $(19,20)$. The total SPPB score is the sum of the scores on the three tests and ranges from 0 to 12: standing balance (the ability to maintain feet side-by-side, semi-tandem, and tandem positions for 10 seconds each), walking speed (for $3 \mathrm{~m}$ at their usual pace), and ability to rise from a chair (stand up from a sitting position once with arms folded at the chest).

Hemoglobin concentration $(\mathrm{g} / \mathrm{dL})$ was collected at both waves and analyzed at the laboratory of the Hospital of the Medical School at the University of São Paulo using an ADVIA 120 system (Siemens Healthcare Diagnostics, Germany). Anemia was defined using the WHO cutoffs - hemoglobin $<12 \mathrm{~g} / \mathrm{dL}$ for women and $<13 \mathrm{~g} / \mathrm{dL}$ for men (21), and anemic individuals were excluded from the analysis.

Covariates were measured in the baseline. We included age, education (in years of schooling), health status, grip strength, and body mass index (BMI). Health status was assessed based on self-reported chronic conditions diagnosed by a physician. We combined these conditions into two groups: 1) the number of cardiometabolic diseases (diabetes, hypertension, stroke, and cardiovascular disease) 
because of their interaction with anemia in physical function (22), and 2) the number of other selfreported chronic conditions (cancer, chronic pulmonary disease, osteoarthritis, and osteoporosis). Grip strength was assessed using the highest value obtained between two attempts using a hand-held dynamometer (Takei Kiki Kogyio TK 1201), with the participant in a sitting position, with elbow and forearm resting in the table, and with palm facing up. BMI was calculated by dividing weight (in kilograms) by height (in meters) squared $\left(\mathrm{kg} / \mathrm{m}^{2}\right)$. Weight was measured using a calibrated scale, and height was measured using a stadiometer fixed to a plain wall, both with the individuals barefoot and wearing light clothing.

\section{Statistical analysis}

Descriptive statistics (weighted means and standard errors) were used to assess the differences in physical performance and selected variables by sex. Sample weights were used to adjust for the complex sampling design. The association between hemoglobin concentration and SPPB scores was analyzed using a repeated mixed-effects linear regression with robust standard errors (23). Repeated mixed-effects regressions handle nested data inherent to repeated observations within individuals to allow for an unequal number of observations across individuals. SPPB score and hemoglobin concentration were treated as continuous variables. Random effects for the intercept were included to allow individuals to vary in the initial level of physical performance. The model included year, age, sex, years of schooling, grip strength, number of cardiometabolic diseases, the total number of other chronic conditions, and BMI. We present the regression coefficients, confidence intervals, and p-values. All regressions were stratified by sex because preliminary analyses indicated a statistically significant interaction between $\mathrm{Hb}$ levels and sex. Based on the results of the adjusted regression models, we calculated the predicted scores of SPPB given various levels of hemoglobin concentration by gender. All data analyses were conducted using the statistical software Stata/SE 16.1.

\section{Results}

Table 1 displays some selected characteristics of participants at the baseline. Most of the evaluated population was female. Women were less educated, had more health conditions, lower grip strength, higher BMI values, lower hemoglobin, and lower SPPB scores in 2010. 
Table 1

Weighted mean and standard errors of selected characteristics of older adults ( $\geq 60$ years old) according to sex in the baseline. SABE Study. São Paulo, Brazil, 2010.

\begin{tabular}{|c|c|c|c|c|}
\hline Characteristics & $\begin{array}{l}\text { Total }(n= \\
\text { 1020) }\end{array}$ & $\begin{array}{l}\text { Women }(n= \\
666)\end{array}$ & $\begin{array}{l}\text { Men }(n= \\
354)\end{array}$ & $p$ \\
\hline Age & $69.5(0.6)$ & $69.8(0.7)$ & $69.0(0.6)$ & 0.081 \\
\hline Education (in years) & $5.3(0.3)$ & $5.0(0.4)$ & $5.8(0.4)$ & 0.003 \\
\hline $\begin{array}{l}\text { Number of cardiometabolic } \\
\text { conditions }\end{array}$ & $1.2(0.04)$ & $1.2(0.04)$ & $1.1(0.06)$ & 0.042 \\
\hline Number of other chronic conditions & $0.7(0.03)$ & $0.9(0.04)$ & $0.3(0.04)$ & $\begin{array}{l}<.001 \\
0.001\end{array}$ \\
\hline Grip strength (kg) & $25.7(0.4)$ & $20.6(0.4)$ & $33.5(0.5)$ & $\stackrel{<}{<.001}$ \\
\hline $\mathrm{BMI}\left(\mathrm{kg} / \mathrm{m}^{2}\right)$ & $28.4(0.2)$ & $29.2(0.3)$ & $27.3(0.2)$ & $\begin{array}{l}<.001 \\
0.001\end{array}$ \\
\hline Hemoglobin concentration $(\mathrm{g} / \mathrm{dL})$ & $14.4(0.05)$ & $13.9(0.05)$ & $15.2(0.07)$ & $\begin{array}{l}<.001 \\
0.001\end{array}$ \\
\hline SPPB score & $9.2(0.1)$ & $9.0(0.1)$ & $9.6(0.1)$ & $\hat{L}_{0.001}$ \\
\hline
\end{tabular}

Table 2 shows the results of the adjusted mixed-effects linear models. Higher hemoglobin levels were associated with higher physical performance scores among older women $(\beta=0.15, p=0.036)$ and men $(\beta=0.18, p=0.038)$. There were reductions in mean levels of SBBP among men and women over time. Higher age was negatively associated with SBBP levels. Higher grip strength was associated with higher SBBP levels. Education was also positively associated with physical performance. Cardiometabolic diseases, as well as other diseases, were negatively associated with SPPB levels. Among women, BMI was negatively associated with SPPB changes. 
Table 2

Repeated mixed-effects linear models for longitudinal changes in physical function (SPPB score) as a function of hemoglobin changes over five years in Brazilian older adults, by sex. SABE Study. São Paulo, Brazil, 2010-2015.

\begin{tabular}{|c|c|c|c|c|}
\hline \multirow[t]{2}{*}{ Variables } & \multicolumn{2}{|l|}{ Men } & \multicolumn{2}{|l|}{ Women } \\
\hline & $\beta$ & $95 \% \mathrm{Cl}$ & $\beta$ & $95 \% \mathrm{Cl}$ \\
\hline \multicolumn{5}{|l|}{ Fixed } \\
\hline Hemoglobin concentration $(\mathrm{g} / \mathrm{dL})$ & $0.18^{*}$ & $(0.01,0.35)$ & $0.15^{\star}$ & $(0.01,0.28)$ \\
\hline Year & $-1.97 * \star \star$ & $(-2.33,-1.62)$ & $-1.86 * \star \star$ & $(-2.07,-1.64)$ \\
\hline Age & $-0.05^{\star \star \star}$ & $(-0.08,-0.02)$ & $-0.12 * \star \star$ & $(-0.14,-0.10)$ \\
\hline Education & $0.09 \star \star \star$ & $(0.04,0.14)$ & $0.07 * \star \star$ & $(0.04,0.10)$ \\
\hline Cardiometabolic conditions & $-0.24^{\star}$ & $(-0.45,-0.03)$ & 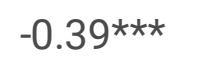 & $(-0.57,-0.22)$ \\
\hline Other chronic conditions & -0.17 & $(-0.50,0.15)$ & $-0.19 *$ & $(-0.38,0.00)$ \\
\hline Grip Strength & $0.08^{\star \star \star}$ & $(0.05,0.10)$ & $0.07 \star \star \star$ & $(0.04,0.09)$ \\
\hline $\mathrm{BMI}\left(\mathrm{kg} / \mathrm{m}^{2}\right)$ & -0.04 & $(-0.10,0.01)$ & $-0.03 *$ & $(-0.06,-0.01)$ \\
\hline Constant & $10.63^{\star \star \star}$ & $(6.53,14.74)$ & $16.74^{\star \star \star}$ & $(14.14,19.34)$ \\
\hline \multicolumn{5}{|l|}{ Random } \\
\hline Intercept & 1.29 & $(1.01,1.66)$ & 1.41 & $(1.26,1.58)$ \\
\hline Residual & 1.68 & $(1.46,1.93)$ & 1.50 & $(1.38,1.64)$ \\
\hline $\mathrm{BIC}$ & 2348.6 & & 4487.62 & \\
\hline AIC & 2301.57 & & 4433.09 & \\
\hline \multicolumn{5}{|c|}{$\begin{array}{l}95 \% \mathrm{Cl}=95 \% \text { Confidence Interval; } \mathrm{BMI}=\text { body mass index; } \mathrm{AIC}=\text { Akaike Information Criterion; } \mathrm{BIC}= \\
\text { Bayesian Information Criterion }\end{array}$} \\
\hline${ }^{*} \mathrm{p}<0.05 ; * \star \mathrm{p}<0.01 ; * \star * \mathrm{p}<0.001$ & & & & \\
\hline
\end{tabular}

Table 3 presents the adjusted predicted scores of SPPB given various levels of $\mathrm{Hb}$ concentration by gender, based on the regression models found in Table 2. Results indicate that those with higher $\mathrm{Hb}$ concentrations have higher SBBP scores. 
Table 3

Predicted scores of Short Physical Performance Battery (SBBP) for older men and women in Brazil. SABE Study. São Paulo, Brazil, 2010-2015.

\begin{tabular}{|lllll|}
\hline \multicolumn{4}{|c}{ Men } & \multicolumn{3}{l|}{ Women } \\
\hline Hemoglobin concentration $(\mathrm{g} / \mathrm{dL})$ & SBBP score & $95 \% \mathrm{Cl}$ & SBBP score & $95 \% \mathrm{Cl}$ \\
\hline 11 & - & - & - & - \\
\hline 12 & - & - & 7.8 & $(7.5,8.1)$ \\
\hline 13 & 8.4 & $(7.9,8.8)$ & 8.0 & $(7.8,8.2)$ \\
\hline 14 & 8.5 & $(8.3,8.8)$ & 8.1 & $(8.0,8.3)$ \\
15 & 8.7 & $(8.5,8.9)$ & 8.3 & $(8.1,8.5)$ \\
16 & 8.9 & $(8.6,9.1)$ & 8.4 & $(8.1,8.7)$ \\
17 & 9.1 & $(8.7,9.4)$ & 8.6 & $(8.1,9.0)$ \\
\hline 18 & 9.2 & $(8.7,9.8)$ & 8.7 & $(8.1,9.3)$ \\
\hline $95 \% \mathrm{Cl}=95 \%$ Confidence Interval & & & & \\
\hline
\end{tabular}

\section{Discussion}

In our results, $\mathrm{Hb}$ levels were positively associated with SPPB in older adults without anemia - those with higher $\mathrm{Hb}$ levels presented better physical performance. To our knowledge, this is the first study to analyze this association in older adults without anemia in LMIC. Our results confirm previous findings by Hirani and colleagues' in which increases in Hb levels are associated with better physical performance indicators, but their results were limited to men in Australia. We show that this finding is also relevant for older women. Therefore, even among older populations without anemia, lower levels of $\mathrm{Hb}$ are associated with worse physical performance.

Previous authors have already suggested that the WHO criteria for defining anemia in adults may not be adequate for older populations. These optimal $\mathrm{Hb}$ cutoffs for clinical decision-making were defined mainly based on statistical distribution considerations using apparently healthy people, rather than being developed through considerations of inflammation, the high prevalence of chronic conditions in older adults, and the physiological reduction in $\mathrm{Hb}$ concentration in the oldest old, factors that would shift the $\mathrm{Hb}$ distribution (1, 24-26).

One cause of the association between $\mathrm{Hb}$ and physical performance is the fact that $\mathrm{Hb}$ is responsible for tissue oxygenation, and lower $\mathrm{Hb}$ values can lead to local hypoxia in skeletal muscle and reduced muscle function (11). This effect is usually described in people with anemia. However, we found that lower $\mathrm{Hb}$ levels, even without anemia, can lead to lower physical function. This finding has not been underexplored in the literature. Zakai et al. (4) suggested that functional decline may occur in close temporal 
association with hemoglobin decline, reinforcing that analyzing $\mathrm{Hb}$ levels may be more informative than only diagnosing anemia, as we showed here.

Steensma and Tefferi (2007) discussed that formal definitions of anemia do not always address the complex relationship between $\mathrm{Hb}$ level and health outcomes. Many factors can affect a healthy person's $\mathrm{Hb}$ value, including ethnic background, altitude of residence, smoking status, and physiologic fluctuations of plasma volume. Hence, the interpretation of blood count results remains the responsibility of the ordering physician, who should also refer to a patient's baseline $\mathrm{Hb}$ level when a previous measurement is available (24). In the same study, Steensma and Tefferi point out that a growing body of medical literature supports a "low-normal" $\mathrm{Hb}$ level associated with a broad range of poorer health-related outcomes. For example, a previous cross-sectional study using data from the 2010 wave of SABE study showed that at a concentration of $12 \mathrm{~g} / \mathrm{dL}$, the probability of mobility difficulty was $9.1 \%$. But at higher levels, the probability of mobility decreased by $7.4 \%$ at $13 \mathrm{~g} / \mathrm{dL}$ and $6.1 \%$ at $14 \mathrm{~g} / \mathrm{dL}$ (8). Furthermore, the association was consistent in both men and women (8).

Another important aspect of our study is the specificity of the relationship between $\mathrm{Hb}$ concentrations and physical function, which was consistent even after adjusting for age, years of education, number of chronic cardiometabolic conditions, number of other chronic diseases, grip strength, and BMI, showing an independent association. Those covariates included in our analyses were largely discussed in the literature as risk factors for worse physical function and disability. Some functional decline is expected with advanced age, even without disease, but this decline is slow and gradual (27). Some authors point out that other factors are determinants for this decline, such as education $(8,28,29)$. It is also well known that physical function decline is higher with chronic diseases $(30,31)$. Our analysis also opted to consider cardiometabolic conditions separately because it was already discussed that those conditions have an important interaction with anemia in physical function $(13,22)$. We also adjusted for grip strength, which is one of the main indicators of physical decline in older ages (32-35), as well as higher BMI, which several publications have indicated, is a risk factor for poor physical performance, mainly in walking and chair-stand tests $(27,32,36,37)$.

We also performed sensitivity analyses to ensure that our results are robust. In analyses including all participants (those with and without anemia), results were similar, showing that the relationship between $\mathrm{Hb}$ levels and SPPB scores is consistent across a wider $\mathrm{Hb}$ range.

Interpretation of our results should consider some limitations. First, as with any other aging cohort, the loss to follow-up and death during the period is considerable. Another study based on SABE data shows that anemia predicts mortality among participants (6); lower hemoglobin values among the non-anemic may as well. This suggests that our study underestimates the effects of $\mathrm{Hb}$ on physical performance. Another limitation is that the time between the two measurements (five years) is considerably long, which could mask shorter fluctuations.

But our study has several strengths. First, it is the first study with a large representative sample of community-dwelling older adults in an LMIC, where a nutritional transition is still ongoing, and the causes 
and consequences of lower levels of $\mathrm{Hb}$ may represent a heavy burden in health services. Also, our analyses considered the levels of $\mathrm{Hb}$ over time in physical function, which is less common as even longitudinal studies typically consider $\mathrm{Hb}$ levels only at the baseline. We also showed effects stratified by sex which is important to target health care actions specifically for men and women. Most importantly, we showed that the effects of $\mathrm{Hb}$ levels are consistent in non-anemic individuals, which may alert health professionals to the importance of evaluating changes in $\mathrm{Hb}$ levels in all older adults, even without the formal diagnosis of anemia.

\section{Conclusions}

In conclusion, our study demonstrates that non-anemic older adults with higher hemoglobin levels presented better physical performance. This result is important because, in clinical practice, most health professionals do not stay alert if $\mathrm{Hb}$ level drops but does not reach the WHO-defined anemia threshold. We raise the possibility that therapeutic interventions (such as improvement in nutritional intake, treatment of possible causes of lower levels of $\mathrm{Hb}$, treatment of chronic conditions that may be impacting $\mathrm{Hb}$ levels, or pharmacological approaches to correct iron deficiency) may be taken with reductions of $\mathrm{Hb}$ levels, even before anemia is diagnosed, to maintain physical function.

\section{Abreviations}

ADL: Activities of Daily Living; AIC: Akaike Information Criterion; BIC: Bayesian Information Criterion; BMI: body mass index; Cl: Confidence Interval; $\mathrm{Hb}$ : hemoglobin; IADL: Instrumental Activities of Daily Living; low and middle-income countries, LMIC; SABE Study: Saúde, Bem-Estar e Envelhecimento (Health, Wellbeing, and Aging Study); SE: Standard Error; SPPB: Short Physical Performance Battery; WHO: World Health Organization.

\section{Declarations}

\section{Ethics approval and consent to participate}

The Research Ethics Committee at the University of São Paulo approved all waves of the SABE Study. Participation was voluntary, and a signed informed consent form was obtained of all participants in each wave. All of the procedures followed the ethical standards of the institutional and national research committee and the 1964 Helsinki declaration.

\section{Consent for publication}

Not applicable.

\section{Availability of data and materials}


The datasets on which the conclusions of this manuscript rely are not available publicly. The datasets used and/or analyzed during the current study are available from YAOD, PI of SABE Study (yedaenf@usp.br), on reasonable request.

\section{Competing interests}

The authors declare that they have no competing interests.

\section{Funding}

This work was supported by Sao Paulo Research Foundation (Fundação de Amparo à Pesquisa do Estado de Sao Paulo - FAPESP) (grant numbers: 2009/53778-3, 2014/23587-0 and 2014/50649-6). FAPESP had no role in the design, analysis, or writing of this article and posed no conflict of interest.

\section{Authors' contributions}

LPC conceived the study, proposed the study design. LPC and FCDA performed data analysis, interpretation and drafted the manuscript. YAOD is the PI of the SABE Study. All authors helped draft the manuscript and interpretation, reviewed and approved the submitted manuscript.

\section{Acknowledgments}

The authors of this article would like to thank Maria Lucia Lebrão (in memory) for her valuable work in coordinating the SABE Study. We also thank all the participants in this study.

\section{References}

1. Chaves PHM, Ashar B, Guralnik JM, Fried LP. Looking at the relationship between hemoglobin concentration and prevalent mobility difficulty in older women. Should the criteria currently used to define anemia in older people be reevaluated? Journal of the American Geriatrics Society. 2002;50(7):1257-64.

2. Penninx BW, Guralnik JM, Wallace R, Pahor M. Anemia is independent risk factor for physical performance decline in old age. Journal of the American Geriatrics Society. 2002;50(4):A35.

3. Penninx BW, Pahor M, Cesari M, Corsi AM, Woodman RC, Bandinelli S, et al. Anemia is associated with disability and decreased physical performance and muscle strength in the elderly. J Am Geriatr Soc. 2004;52(5):719-24.

4. Zakai NA, Katz R, Hirsch C, Shlipak MG, Chaves PHM, Newman AB, et al. A prospective study of anemia status, hemoglobin concentration, and mortality in an elderly cohort - The cardiovascular health study. Archives of Internal Medicine. 2005;165(19):2214-20.

5. den Elzen WPJ, Willems JM, Westendorp RGJ, de Craen AJM, Assendelft WJJ, Gussekloo J. Effect of anemia and comorbidity on functional status and mortality in old age: results from the Leiden 85plus Study. Canadian Medical Association Journal. 2009;181(3-4):151-7. 
6. Corona LP, de Oliveira Duarte YA, Lebrão ML. Markers of nutritional status and mortality in older adults: The role of anemia and hypoalbuminemia. Geriatr Gerontol Int. 2017.

7. Chaves PHM, Xue QL, Guralnik JM, Ferrucci L, Volpato S, Fried LP. What constitutes normal hemoglobin concentration in community-dwelling disabled older women? Journal of the American Geriatrics Society. 2004;52(11):1811-6.

8. Pires Corona L, Drumond Andrade FC, de Oliveira Duarte YA, Lebrao ML. The Association of Hemoglobin Concentration with Disability and Decreased Mobility among Older Brazilians. J Nutr Health Aging. 2014;18(3):336-41.

9. Payne CF, Davies JI, Gomez-Olive FX, Hands KJ, Kahn K, Kobayashi LC, et al. Cross-sectional relationship between haemoglobin concentration and measures of physical and cognitive function in an older rural South African population. J Epidemiol Community Health. 2018;72(9):796-802.

10. Marzban M, Nabipour I, Farhadi A, Ostovar A, Larijani B, Darabi AH, et al. Association between anemia, physical performance and cognitive function in Iranian elderly people: evidence from Bushehr Elderly Health (BEH) program. BMC Geriatr. 2021;21(1):329.

11. Tseng SH, Lee WJ, Peng LN, Lin MH, Chen LK. Associations between hemoglobin levels and sarcopenia and its components: Results from the I-Lan longitudinal study. Exp Gerontol. 2021;150:111379.

12. Hirani V, Naganathan V, Blyth F, Le Couteur DG, Seibel MJ, Waite LM, et al. Low Hemoglobin Concentrations Are Associated With Sarcopenia, Physical Performance, and Disability in Older Australian Men in Cross-sectional and Longitudinal Analysis: The Concord Health and Ageing in Men Project. J Gerontol A Biol Sci Med Sci. 2016;71(12):1667-75.

13. Yoshimura $Y$, Wakabayashi $H$, Shiraishi A, Nagano F, Bise T, Shimazu S. Hemoglobin Improvement is Positively Associated with Functional Outcomes in Stroke Patients with Anemia. J Stroke Cerebrovasc Dis. 2021;30(1):105453.

14. Pires Corona L, Drumond Andrade FC, de Oliveira Duarte YA, Lebrao ML. The Relationship between Anemia, Hemoglobin Concentration and Frailty in Brazilian Older Adults. J Nutr Health Aging. 2015;19(9):935-40.

15. Silva CLÁ, Lima-Costa MF, Firmo JOA, Peixoto SV. Hemoglobin level in older adults and the association with nutritional status and use of health services: the Bambuí Project. Cad Saude Publica. 2012;28(11):2085-94.

16. Bosco RdM, Assis EPS, Pinheiro RR, Queiroz LCVd, Pereira LS, Antunes CMF. Anemia and functional capacity in elderly Brazilian hospitalized patients. Cadernos de Saúde Pública. 2013;29:1322-32.

17. Sawada M, Kubota N, Sekine R, Yakabe M, Kojima T, Umeda-Kameyama Y, et al. Sex-related differences in the effects of nutritional status and body composition on functional disability in the elderly. PLoS One. 2021;16(2):e0246276.

18. Li Q, Chen X, Han B. Red blood cell distribution width is associated with frailty in older inpatients in China: Sex differences in a cross-sectional study. Experimental Gerontology. 2021;150:111392. 
19. Guralnik JM, Simonsick EM, Ferrucci L, Glynn RJ, Berkman LF, Blazer DG, et al. A short physical performance battery assessing lower-extremity function - association with self-reported disability and prediction of mortality and nursing-home admission. Journals of Gerontology. 1994;49(2):M85M94.

20. Guralnik JM, Ferrucci L, Simonsick EM, Salive ME, Wallace RB. Lower-extremity function in persons over the age of 70 years as a predictor of subsequent disability. New England Journal of Medicine. 1995;332(9):556-61.

21. WHO. Iron deficiency anaemia. Geneva; 2001.

22. Chaves PHM, Woodman RC, Fried LP. Anemia and cardiovascular disease (CVD) synergistically interact to increase the risk of frailty in community-dwelling older women. Blood. 2004;104(11):3137.

23. McCulloch CE, Searle SR. Generalized Linear Mixed Models (GLMMs). Generalized, Linear, and Mixed Models: John Wiley \& Sons, Inc.; 2000. p. 220-46.

24. Steensma DP, Tefferi A. Anemia in the elderly: How should we define it, when does it matter, and what can be done? Mayo Clinic Proceedings. 2007;82(8):958 - 66.

25. Eisenstaedt R, Penninx BW, Woodman RC. Anemia in the elderly: current understanding and emerging concepts. Blood Rev. 2006;20(4):213-26.

26. Paltiel O, Clarfield AM. Anemia in elderly people: Risk marker or risk factor? Canadian Medical Association Journal. 2009;181(3-4):129-30.

27. Ramírez-Vélez R, Pérez-Sousa MA, Venegas-Sanabria LC, Cano-Gutierrez CA, Hernández-Quiñonez PA, Rincón-Pabón D, et al. Normative Values for the Short Physical Performance Battery (SPPB) and Their Association With Anthropometric Variables in Older Colombian Adults. The SABE Study, 2015. Frontiers in Medicine. 2020;7(52).

28. Pothisiri W, Prasitsiriphon O, Aekplakorn W. Extent of aging across education and income subgroups in Thailand: Application of a characteristic-based age approach. PLoS One. 2020;15(12):e0243081.

29. Koster A, Bosma H, Broese van Groenou MI, Kempen GIJM, Penninx BWJH, van Eijk JT, et al. Explanations of socioeconomic differences in changes in physical function in older adults: results from the Longitudinal Aging Study Amsterdam. BMC Public Health. 2006;6(1):244.

30. Fuentes-Abolafio IJ, Stubbs B, Pérez-Belmonte LM, Bernal-López MR, Gómez-Huelgas R, CuestaVargas Al. Physical functional performance and prognosis in patients with heart failure: a systematic review and meta-analysis. BMC cardiovascular disorders. 2020;20(1):512-.

31. Hay SI, Abajobir AA, Abate KH, Abbafati C, Abbas KM, Abd-Allah F, et al. Global, regional, and national disability-adjusted life-years (DALYs) for 333 diseases and injuries and healthy life expectancy (HALE) for 195 countries and territories, 1990-2016: a systematic analysis for the Global Burden of Disease Study 2016. The Lancet. 2017;390(10100):1260-344.

32. Hardy R, Cooper R, Aihie Sayer A, Ben-Shlomo Y, Cooper C, Deary IJ, et al. Body Mass Index, Muscle Strength and Physical Performance in Older Adults from Eight Cohort Studies: The HALCyon Programme. PLOS ONE. 2013;8(2):e56483. 
33. Cawthon PM, Travison TG, Manini TM, Patel S, Pencina KM, Fielding RA, et al. Establishing the Link Between Lean Mass and Grip Strength Cut Points With Mobility Disability and Other Health Outcomes: Proceedings of the Sarcopenia Definition and Outcomes Consortium Conference. The Journals of Gerontology: Series A. 2019;75(7):1317-23.

34. Dent E, Morley JE, Cruz-Jentoft AJ, Arai H, Kritchevsky SB, Guralnik J, et al. International Clinical Practice Guidelines for Sarcopenia (ICFSR): Screening, Diagnosis and Management. J Nutr Health Aging. 2018;22(10):1148-61.

35. Cruz-Jentoft AJ, Bahat G, Bauer J, Boirie Y, Bruyère O, Cederholm T, et al. Sarcopenia: revised European consensus on definition and diagnosis. Age Ageing. 2019;48(4):601.

36. Kim S, Leng XI, Kritchevsky SB. Body Composition and Physical Function in Older Adults with Various Comorbidities. Innovation in Aging. 2017;1(1).

37. Chatindiara I, Williams V, Sycamore E, Richter M, Allen J, Wham C. Associations between nutrition risk status, body composition and physical performance among community-dwelling older adults. Australian and New Zealand Journal of Public Health. 2019;43(1):56-62. 